\title{
Ultrastructural Changes in the Wall during Germ-tube Formation from Blastospores of Candida albicans
}

\author{
By A. CASSONE, N. SIMONETTI* AND V. STRIPPOLI \\ Institute of Microbiology, University of Rome, Rome, ooroo, Italy
}

(Received 7 August 1972)

\begin{abstract}
SUMMAR Y
The wall of a blastospore of Candida albicans is organized in a multilayer structure with amorphous, granular and fibrous components of various electron densities. Striking modifications in this structural pattern occurred when a blastospore was induced to form a germ tube, as shown by fluorescence microscopy of primulin-treated organisms and electron microscopy of thin sections. The essential 'building' change was the formation from inside the blastospore wall of an electron-transparent layer in which materials of various shape and dimensions were embedded. This layer grew out through a definite zone of the blastospore wall, thus forming an early germ-tube. Germ-tube emergence from the blastospore was made possible by degradative changes of wall structures overlaying the electron-transparent layer, caused probably by combined mechanical and lytic (enzymatic) actions. However, each component of these structures was resynthesized at various moments of germ-tube elongation. Therefore the wall of the germ tube had a stratification comparable to that of a blastospore wall; only quantitative differences in the thickness of the constitutive layers existed between them. Some data suggested that the electron-transparent layer that developed during germtube formation was rich in chitin.
\end{abstract}

\section{INTRODUCTION}

Dimorphism in yeasts is a reversible transformation of a yeast-phase organism to a mycelial one (Romano, 1966). A dimorphic process starts in Candida albicans when a blastospore produces a short filament, called the 'germ or pseudogerm tube' (Hill \& Gebhardt, 1956; Taschdjian \& Kozinn, 1957; Mackenzie, 1962; Mardon, Hurst \& Balish, 197I), which can later evolve into a true mycelium (Mackenzie, I964; Simonetti \& Cassone, 1969). Germ-tube production is of a great value for laboratory diagnosis of $C$. albicans (Taschdjian, Burchall \& Kozinn, 1960; Mackenzie, I962; Buckley \& Van Uden, 1963). Moreover, these particular morphological elements seem to play an important role in the pathogenesis of candidiasis because their appearance in vivo is related to the outbreak of illness (Rogers, I957; Taschdjian \& Kozinn, I957; Gresham \& Burns, I960; Gresham \& Whittle, I961; Kozinn \& Taschdjian, 1962; Simonetti \& Strippoli, 1972). Nevertheless, little or nothing is known about the mechanism of germ-tube formation in C. albicans.

We have therefore undertaken morphological and biochemical researches on germ-tube formation, having primarily focused our attention on the role played by the wall in this process.

* Present address: Institute of Microbiology, University of Camerino, Camerino, 62032, Italy. 


\section{METHODS}

Candida albicans (Robin) Berkout, strain 44, from the Istituto Superiore di Sanità, Rome, Italy, was used throughout this study. It was grown on Sabourand agar medium at $37^{\circ} \mathrm{C}$.

Organisms were scraped off the medium and washed several times with distilled water at room temperature. Germ tubes were obtained after inoculation of $0.2 \mathrm{ml}$ of a suspension of yeast-phase organisms (blastospores) at an extinction $E_{600 \mathrm{~nm}}^{1 \mathrm{~cm}}=\mathrm{I} \cdot 0$ into a germination mixture consisting of swine serum diluted ( $1: 2.5)$ with water containing cysteine (Merck, Darmstadt, Germany; $50 \mu \mathrm{g} / \mathrm{ml}$ and sodium thioglycollate (Difco Laboratories, Michigan, Detroit, U.S.A.; $20 \mu \mathrm{g} / \mathrm{ml}$ ) to a final volume of I $\mathrm{ml}$. The mixture was kept with constant stirring at $37^{\circ} \mathrm{C}$ for $2 \mathrm{~h}$. Almost complete germination ( 95 to $100 \%$ ), as estimated by darkfield microscopy, was reproducibly obtained.

For fluorescence microscopy, the same cultural conditions were used except that primulin (Fluka, Buchs, Switzerland) was added to the germination mixture to a final concentration of $0.1 \mathrm{mg} / \mathrm{ml}$. Preliminary experiments had shown that, at this concentration, primulin did not affect germ-tube formation. After incubation, the organisms were washed with a solution of primulin $(0.1 \mathrm{mg} / \mathrm{ml})$ and observed under a Leitz Orthomat microscope in dark field.

Electron-microscopic observations were carried out on specimens prepared by the technique described by Djaczenko \& Cassone (1972). Germinated samples were washed carefully with phosphate buffer $(\mathrm{pH} 7 \cdot 2 ; 0 . \mathrm{I} \mathrm{M})$, centrifuged, and the pellet fixed in a mixture of I \% acrolein (Fluka) and I \% TAPO (tris-I aziridinyl-phosphine oxide; Polysciences, Rydal, Pennsylvannia, U.S.A.) in phosphate buffer for $15 \mathrm{~min}$ at room temperature. After a brief washing in the same buffer the pellet was postfixed in aqueous $\mathrm{OsO}_{4}(4 \%$ w/v) overnight, then washed and stained for $8 \mathrm{~h}$ at room temperature with uranyl acetate $(0.5 \%, \mathrm{w} / \mathrm{v})$ in Michaelis buffer, $\mathrm{pH} 5.4$. The samples were dehydrated in ethanol and acetone, infiltrated in styrene, and embedded in Vestopal. Ultrathin sections were cut with a Porter-Blumm MT-2 ultramicrotome, stained with lead citrate (Reynolds, 1963) and uranyl acetate, and observed in a Siemens I A Elmiskop operating at $80 \mathrm{kV}$.

\section{RESULTS}

\section{Primulin-induced fluorescence microscopy}

This technique allowed us to follow the major morphological changes occurring throughout germination and to establish the fate of the germinated elements. Evaluation of the intensity and the quality of the fluorescence can give useful information on the organization of the wall (Beran, I968).

The emergence of a germ tube from blastospore of Candida albicans was seen as a local protrusion of the cytoplasm enclosed by a thin-wall layer having a very slight greenishyellow fluorescence (Fig. I $a, b, c$ ). In contrast to the situation in budding organisms, no strongly fluorescent ridges at the base of the emerging element were seen. Even during elongation the germ-tube wall was poorly fluorescent as compared to the blastospore wall (Fig. I $c, d$ ), but the difference diminished after further mycelial transformation of the germ tube. Formation of a septum at a variable distance from the point of germ-tube emergence and branching of the long filament completed the mycelial transformation of the elongated germ tube. Both the septum and the branch origin were strongly fluorescent (Fig. I $d, e$ ). 

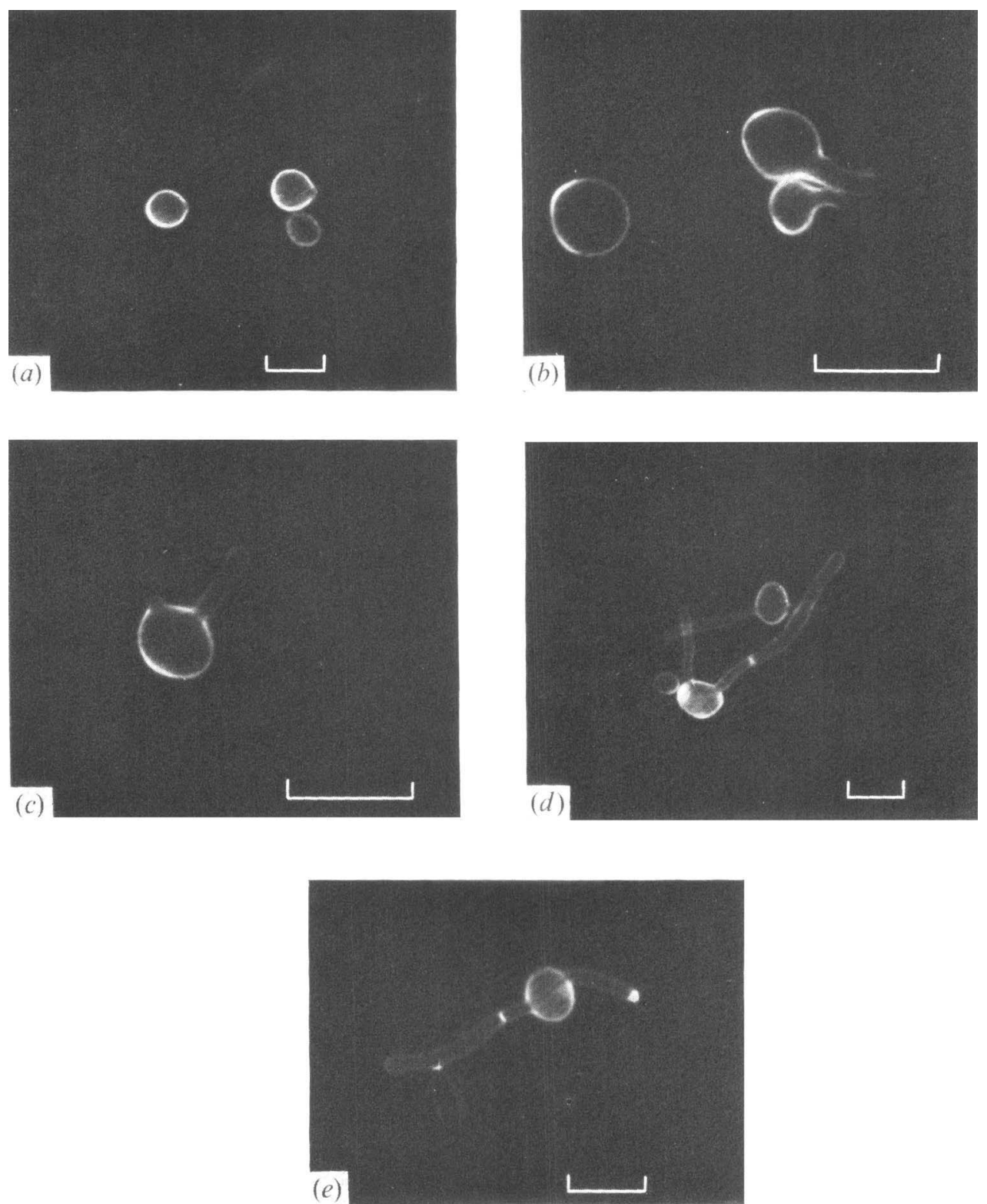

Fig. I ( $a-e)$. Stages in the development of a germ tube from blastopore of Candida albicans, as seen by fluorescence microscopy of primulin-treated cells. For explanation, see text. The length of the bar corresponds to $10 \mu \mathrm{m}$. 

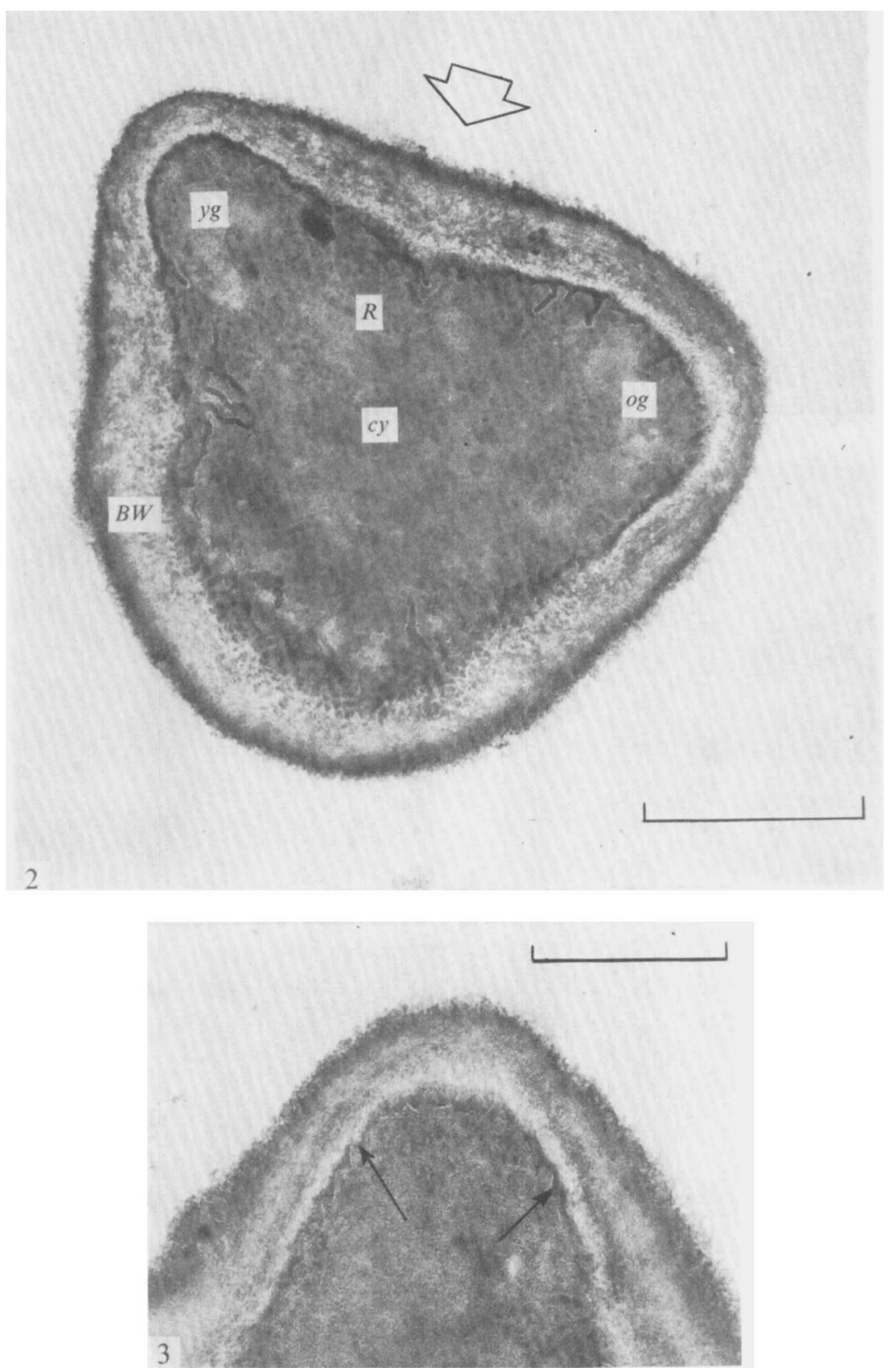

Fig. 2 to 7. Electron micrographs of Candida albicans fixed by acrolein-TAPO-osmium method. The contrast of intracytoplasmic membranes in acrolein-TAPO-osmium-fixed organisms is very low so that cytoplasmic organelles are seen only as areas of low density in the cytoplasm. Abbreviations are: $G T=$ germ tube; $G T W=$ germ-tube wall; $B=$ blastopore; $B W=$ blastospore wall; $c y=$ cytoplasm; $R=$ cytoplasmic granules, presumably ribosomes. Other abbreviations are listed under the respective Figure. The length of the bar corresponds to $0.5 \mu \mathrm{m}$.

Fig. 2. A young blastospore of Candida albicans showing definite zones of the wall and typical changes in germ-tube formation. The zone marked $y g$ may be interpreted as representing a very early stage in germ-tube formation, while the zone marked og seems in a more advanced stage. Note the distinct stratification of the blastopore wall in the zone indicated by an arrow.

Fig. 3. A higher magnification of blastospore wall engaged in germ-tube formation. Note the regular crenulate appearance of the innermost layer of the wall fused with the external leaflet of the plasmalemma (arrows) and the apical accumulation of electron-transparent material in continuity with the inner electron-transparent layer of the blastospore wall (see also Fig. 2). 

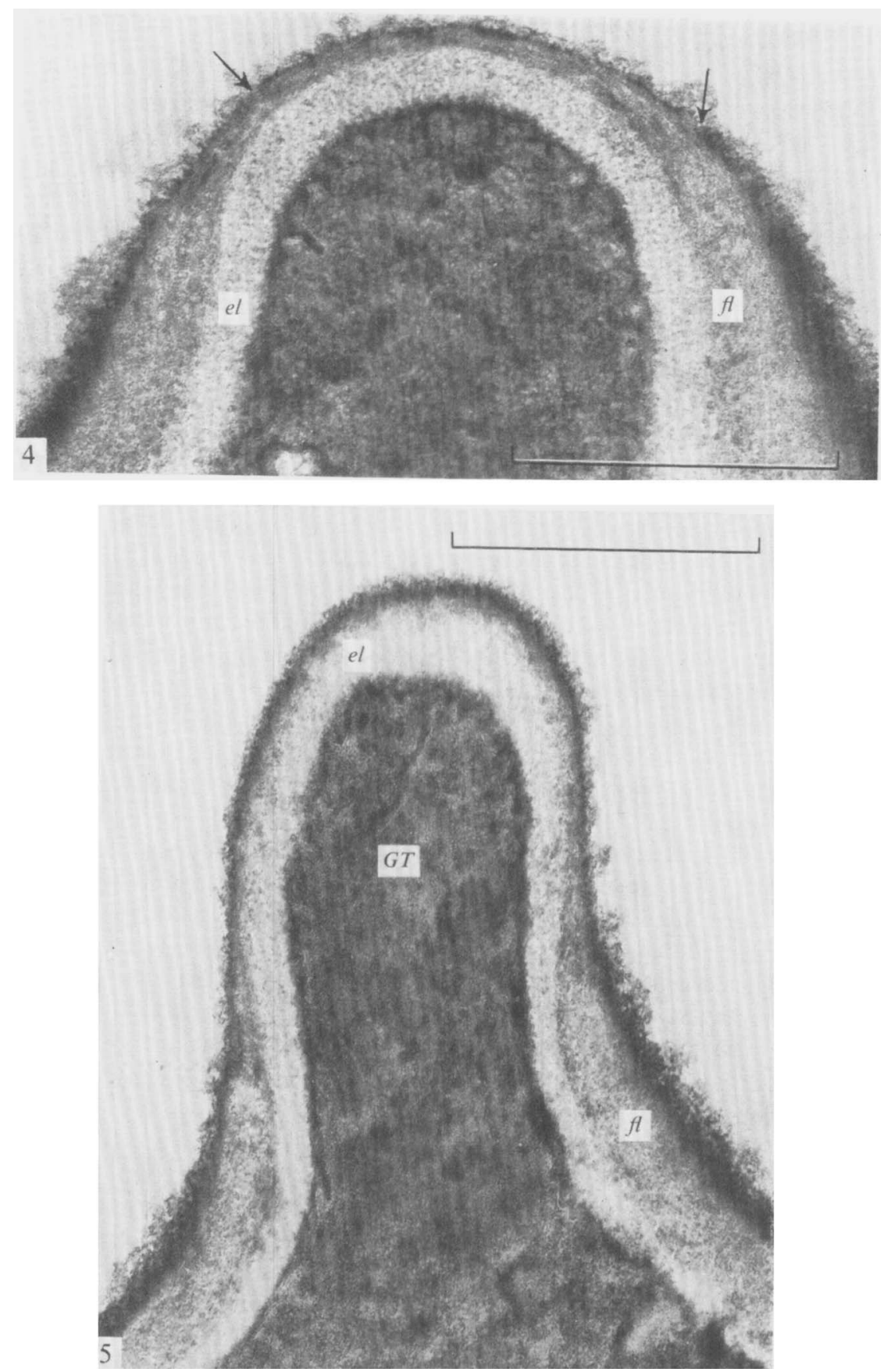

Fig. 4. The emerging electron-transparent layer $(e l)$ of the incipient germ tube has a well-defined morphological outline and a clear-cut interface with the overlaying fibrous layer $(f)$, which seems compressed at the tip. Areas of lysis of the outer components of the blastospore wall are indicated by arrows.

Fig. 5. The stage of germ-tube emergence, in which the fibrous component $(f)$ of blastopore wall seems to open up, so allowing for the outgrowth of the underlying electron-transparent layer $(e l)$. This is covered by material which is probably synthesized during this stage (compare with Fig. 4). 


\section{Electron microscopy}

As reported by Djaczenko \& Cassone (1972), the wall of yeast-phase Candida albicans fixed by the acrolein-TAPO-osmium method showed five distinct layers with amorphous, granular and fibrous structures. The disposition of the layers can be seen in Fig. 2. The first, starting from the outside, was a fibro-granular or floccular layer which often showed some discontinuities and was sometimes diminished or absent in buds and very young organisms. The second layer was formed by an amorphous highly dense material, while the third was rich in optically dense, 30 to $40 \AA$ thick, filaments. The fourth was an electrontransparent layer with interspersed medium-density material of various shape and dimensions. Often, the third and fourth layers were not well separated and showed some sharing of the same elementary components. Finally, a homogeneously dense material fused with the external leaflet of the plasmalemma constituted the fifth, innermost layer of the wall.

During germ-tube formation the layers underwent striking modifications in the amount, morphology and orientation of their components. The changes are shown in Fig. 2 to 5 . At the site of germination, the innermost dense layer of the blastospore wall had a more regular outline with few invaginations into the cytoplasm; it became continuous with the innermost layer of germ-tube wall. A progressive accumulation of electron-transparent material was seen in the overlying layer (the fourth one of the blastospore wall), which, after thickening, outgrew in the form of an incipient germ tube. In the early stages of the process, such a growing layer was filled with medium-density material morphologically similar to that seen, in a more disperse form, in the fourth layer of the blastospore wall. Often this filling material was no longer discernible in ensuing developmental stages. As shown in Fig. 5, the main component of the emerging germ-tube wall was an electron-transparent layer, continuous with the fourth layer of the blastospore wall, but thicker and betterdefined morphologically.

Formation of a germ tube required extensive modifications to the structures which, in the blastospore wall, were superimposed upon the electron-transparent layer. Owing to the growth of this layer, the fibrous component of the third layer was first seen arranged in close bundles parallel to the germinative surface of the organism (Fig. 4); then it seemed to open out during emergence of the underlying layer (Fig. 5). At the same time, the outer layers underwent progressive lysis; the outermost material disappeared in an early stage of germ-tube formation while the amorphous matrix of the second layer, whose lytic areas are clearly seen in Fig. 4, was degraded soon after. Nevertheless, at a slightly more advanced stage of germination, the outer components consistently reappeared (Fig. 5) - an observation suggesting that they were rapidly resynthesized.

Once definitely formed, the germ tube elongated by apical growth (Fig. 5 to 7 ). During elongation, an increased synthesis of amorphous and fibrillar components occurred so that five distinct layers of the wall were again clearly visible in longitudinal sections (Fig. 6). However, renewed synthesis and assembly of wall material did not cause a complete reversion of the germ-tube wall into the configuration of the blastospore wall. The two structures differed in the thickness and morphological aspect of the inner layers (Fig. 7). The total thickness of the germ-tube wall ranged from $\mathrm{I} 20$ to $\mathrm{I} 35 \mathrm{~nm}$ - approximately half that of the wall of a yeast-phase organism. 

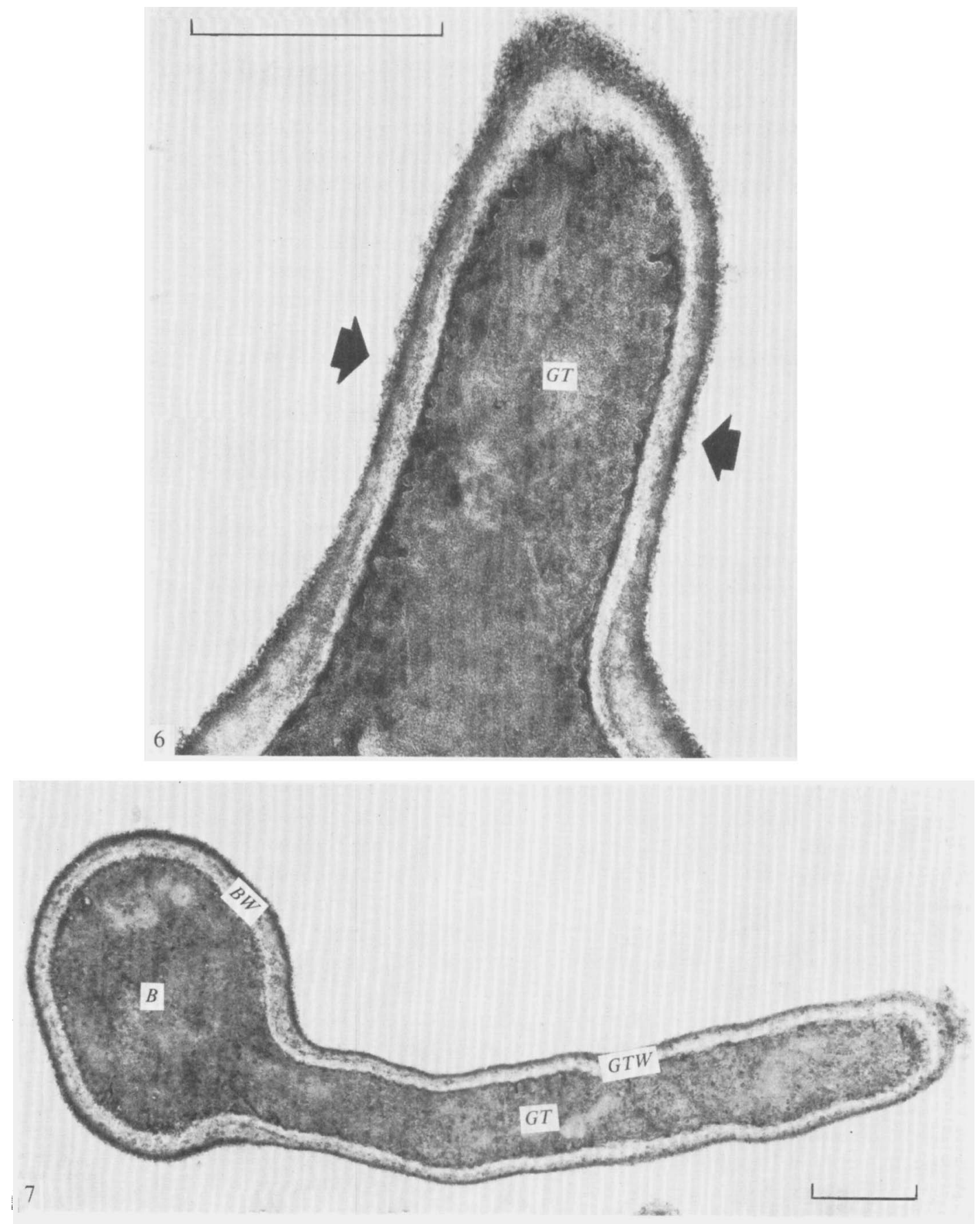

Fig. 6. An advanced stage of germ-tube formation, in which the germ-tube wall has gained a multilayered appearance comparable with that of the blastospore wall. Five layers of the germ-tube wall are clearly seen, indicated by arrows.

Fig. 7. A fully developed germ tube. Note that the electron-transparent layer continues around the germ tube for all its length. 


\section{DISCUSSION}

Streiblova, Beran \& Pokorny (I964) and Beran (I968) suggested that primulin is adsorbed on the surface fibrils of the yeast wall, in which case variations in the fluorescence of the wall during morphogenesis should depend on changes in the amount, spatial arrangement, and compactness of the fibrillar structures, which are probably glucan in nature. In accounting for a very slight fluorescence in early germ-tube wall, two features shown by electron microscopy seem to agree with the suggestion of Streiblova et al. (1964). Firstly, the main component of the early germ-tube wall did not show a fibrous structure; secondly, at the site of germination, the fibrous component of the intermediate (third) layer of the mother wall first thinned, was then re-arranged, and ultimately was opened up. In addition, it is possible that outer, non-fibrillar materials were also involved in primulin adsorption on the wall of Candida albicans: their degradation during the early stages of germination could have contributed to a diminished fluorescence of the wall.

The appearance of a well-defined, thick, electron-transparent layer is an essential ultrastructural change in the wall of Candida albicans at the site of germination. An electrontransparent layer is also developed inside the wall in germinating spores of various other fungi (Hawker \& Abbott, I963; Marchant, I966; Gull \& Trinci, I97I). But, in contrast to classical germinative processes (Burnett, 1968), in $C$. albicans a swelling preceding or accompanying blastospore germination was not observed. Our findings are also somewhat different from those reported by Tokunaga, Tokunaga \& Egashira (1969) in permanganatefixed C. albicans. However, these authors did not show the early stages of germ-tube formation which are the most informative with regard to changes that take place in wall organization. Like Gull \& Trinci (197I), we have often found that permanganate gives misleading information on the ultrastructure of the wall.

Another problem is concerned with the chemical nature of the electron-transparent layer. It should contain chemical components present also in the blastospore wall as suggested by the fact, reported by Chattaway, Holmes \& Barlow (1968), that quantitative but not qualitative differences in chemical composition exist between blastocellular and mycelial forms of Candida albicans. Morphological data reported in this paper support this view because the electron-transparent layer of the germ-tube wall had its diminished and, often, ill-defined counterpart in the fourth layer of the blastospore wall. Cytochemical reaction for polysaccharides (Thiery, 1967) showed that the electron-transparent layer was poorly reactive as compared with the other layers of the germ-tube wall. Among the polysaccharide complexes of the wall, containing mannan, glucan and chitin, it is the chitin that is expected to be unreactive toward the cytochemical method of Thiery. The larger amount of chitin in the mycelial form of $C$. albicans (Chattaway et al. 1968) correlates well with our finding. A preferential localization of chitin in the electron-transparent layer is also suggested by the fact that yeast structures known to be chitin-rich appear essentially electron-transparent (Bacon, Davidson, Jones \& Taylor, 1966; Cabib \& Bowers, I97I). Chitin seems to play an important role in budding (Marchant \& Smith, I968; Kreger-Van Rij \& Veenhuis, I969; Cabib \& Bowers, I97I) and septum formation in yeast (Cabib \& Farkas, I97I); that a similar role might be played by chitin in germ-tube formation in $C$. albicans is a working hypothesis that we are now investigating.

The authors thank Mr B. Pasquetti for his excellent aid in preparing the samples for electron microscopy. This work was in part supported by a research grant from C.N.R., Italy. 


\section{REFERENCES}

Bacon, J. S. D., Davidson, E. D., Jones, D. \& Taylor, I. F. (I966). The location of chitin in the yeast cell wall. Biochemical Journal Ior, $36 c-38 c$.

Beran, K. (1968). Budding of yeast cells, their scars and ageing. In Advances in Microbial Physiology, vol. 2, p. I48. Edited by A. H. Rose and J. F. Wilkinson. London and New York: Academic Press.

BuCkley, H. R. \& VAN UdEN, N. (1963). The identification of Candida albicans within two hours by the use of an egg white slide preparation. Sabouraudia 2, 205-208.

BURnetT, J. H. (1968). Fundamentals of Mycology, pp. I79-187. London: Edward Arnold.

CABIB, E. \& Bowers, B. (197I). Chitin and yeast budding. Localization of chitin in yeast bud scars. Journal of Biological Chemistry 246, I 52-I 59.

CABIB, E. \& FARKAS, V. (I97I). The control of morphogenesis: an enzymatic mechanism for the initiation of septum formation in yeast. Proceeding of the National Academy of Sciences of the United States of America 68, 2052-2056.

Chattaway, F. W., Holmes, M. R. \& Barlow, A. J. E. (1968). Cell wall composition of the mycelial and blastospore forms of Candida albicans. Journal of General Microbiology 51, 367-376.

Djaczenko, W. \& CASsone, A. (1972). Visualization of new ultrastructural components in the cell wall of Candida albicans with fixatives containing TAPO. Journal of Cell Biology 52, 186-190.

Gresham, G. A. \& Burns, M. (1960). Tissue invasion by Candida. In Progress in Biological Sciences in Relation to Dermatology, pp. 174-183. London: Cambridge University Press.

Gresham, G. A. \& Whittle, C. H. (196I). Studies of the invasive, mycelial form of Candida albicans. Sabouraudia $\mathbf{I}, 30-33$.

Gull, K. \& TRINCI, A. P. J. (1971). Fine structure and spore germination in Botrytis cinerea. Journal of General Microbiology 68, 207-220.

Hawker, L. E. \& Aвbott, P. M. (1963). An electron microscopic study of maturation and germination of sporangiospores of two species of Rhizopus. Journal of General Microbiology 32, 295-298.

Hill, D. W. \& GebhardT, L. P. (1956). Morphological transformation of Candida albicans in tissues of mice. Proceeding of the Society for Experimental Biology and Medicine 92, 640-644.

Kozinn, P. J. \& TASChdjan, C. L. (1962). Enteric candidiasis: diagnosis and clinical considerations. Pediatrics 30, $7 \mathrm{I}-85$.

Kreger-van RiJ, N. J. W. \& Veenhuis, M. (I969). A study of vegetative reproduction in Endomycopsis platypodis by electron microscopy. Journal of General Microbiology 58, 34 I-346.

Mackenzie, D. W. R. (1962). Serum tube identification of Candida albicans. Journal of Clinical Pathology $15,563-565$.

MackenzIE, D. W. R. (1964). Morphogenesis of Candida albicans in vivo. Sabouraudia 3, 225-232.

MARChant, R. (1966). Fine structure and spore germination in Fusarium culmorum. Annals of Botany 30, $44 \mathrm{I}-445$.

Marchant, R. \& Smith, D. G. (1968). Bud formation in Saccharomyces cerevisiae and a comparison with the mechanism of cell division in other yeasts. Journal of General Microbiology 53, 163-169.

Mardon, D. N., Hurst, S. K. \& Balish, E. (197I). Germ-tube production by Candida albicans in minimal liquid culture media. Canadian Journal of Microbiology 17, 85 I-856.

ReYNOLDs, E. S. (1963). The use of lead citrate at high pH as an electron-opaque stain in electron microscopy. Journal of Cell Biology 17, 208-2 12.

Rogers, K. B. (I957). An aid to the differentiation between cases of moniliasis and monilic carriers. Journal of Clinical Pathology 10, 406-407.

Romano, A. H. (1966). Dimorphism. In The Fungi, vol. II, pp. 181-209. Edited by G. C. Ainsworth \& A. S. Sussman. New York and London: Academic Press.

Simonetti, N. \& CASSOne, A. (1969). Dinamica della formazione di tubi germinativi in Candida albicans. Atti XV Congresso della Società Italiana di Microbiologia, vol. 2, pp. 150-154. Torino: Saint Vincent.

SimonetTi, N. \& STRippoli, V. (1972). Pathogenicity of the $\mathrm{Y}$ forms as compared to $\mathrm{M}$ forms in experimentally induced Candida albicans infections. Mycopathologia et Mycologia Applicata (in the press).

Streiblova, E., Beran, K. \& Pokorny, V. (I964). Multiple scars, a new type of yeast scar in apiculate yeasts. Journal of Bacteriology 88, I I04-I I I .

TAschdjian, C. L. \& Koznin, P. J. (1957). Laboratory and clinical studies on candidiasis in the newborn infant. Journal of Pediatrics 5o, 426-433. 
Taschditan, C. L., Burchall, J. J. \& KozinN, P. J. (1960). Rapid identification of Candida albicans by filamentation in serum and serum substitutes. Journal of Disease in Children 99, 212-215.

THIERY, J. P. (1967). Mise en evidence des polysaccharides sur coupes fines en microscopie electronique. Journal de Microscopie 6, 987-1018.

Tokunaga, J., Tokunaga, M. \& Egashira, T. (1969). Electron microscopical studies on growing fungal cells. II. Cell wall formation in budding and germinating blastopores of genus Candida. Japanese Journal of Bacteriology 24, 676-682. 